\title{
Prevalence and attitudes towards using protein supplements among female gym users: an only survey
}

\author{
M.H. Alhussain and W. Abdulhalim \\ Department of Food Science and Nutrition, College of Food and Agriculture Sciences, King Saud University, \\ Saudi Arabia
}

Protein supplements have become a widespread practice amongst athletes and gym users worldwide ${ }^{(1-4)}$. However, the use of protein supplements among female gym users in Saudi Arabia has not yet been investigated. The aim of this study was to investigate the prevalence of protein supplement usage among female gym users and their attitudes towards protein supplementation in Riyadh, Saudi Arabia

In this cross-sectional study, 502 female gym users aged $\geq 18$ years completed a structured, self-administered online questionnaire on the usage of protein supplementation. Socio-demographic information, anthropometry, health status, exercise frequency, attitudes, and knowledge regarding protein supplements were obtained. Statistical analysis was performed using SPSS 23. Independent t-test was used to check mean differences for continuous variables. Pearson's chi-square tests were used to identify associations between protein supplement use and categorical variables.

The overall prevalence rate of protein supplement use among the study respondents was $36.3 \%$. There were positive associations between the use of protein supplements and educational level $(p<0.05)$, the duration of being a gym member $(p<0.05)$ and frequency of gym visits per week $(\mathrm{p}<0.05)$. Whey protein was the predominantly used supplement $(57.8 \%)$ and the reason attributed to the use of protein supplement was muscle building $(53.9 \%)$. The main sources of information regarding protein supplement use included the internet $(30.2 \%)$ followed by gym coaches $(25.3 \%)$.

Our findings demonstrated that approximately third of females exercising in gyms use protein supplements, and most rely on internet sources for decision-making of protein supplements use. Nutritional education and consultations regarding protein supplement use are warranted.

\section{Acknowledgements}

The authors would like to thank all gym users who voluntarily participated in the Study.

\section{References}

1. Erdman KA, Fung TS \& Reimer RA (2006) Med Sci Sports Exerc 38, 349-356.

2. Maughan RJ, Greenhaff PL \& Hespel P (2011) J Sports Sci 29, S57-S66.

3. Garthe I \& Maughan RJ (2018) Int J Sport Nutr Exerc Metab 28, 126-138.

4. Bianco A, Mammina C, Paoli A et al. (2011) J Int Soc Sports Nutr 8, 1-6. 